\title{
A High-Energy Ball Milling as a Useful Technique for the Synthesis of $\mathrm{CaCu}_{3} \mathrm{Ti}_{4} \mathrm{O}_{12}$ Electroceramics
}

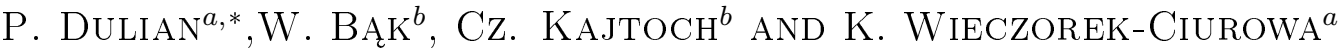 \\ ${ }^{a}$ Cracow University of Technology, Faculty of Chemical Engineering and Technology, \\ Warszawska 24, 31-155 Kraków, Poland \\ ${ }^{b}$ Pedagogical University, Institute of Physics, Podchorążych 2, 30-084 Kraków, Poland
}

This paper shows that $\mathrm{CaCu}_{3} \mathrm{Ti}_{4} \mathrm{O}_{12}$ (CCTO) can be synthesized through the high-energy ball milling of $\mathrm{CaO}, \mathrm{CuO}$ and $\mathrm{TiO}_{2}$ powders. The dielectric characterization of CCTO obtained mechanochemically as well as, for comparison, by a high-temperature method is presented. Moreover, it is illustrated that zirconium oxide in contrast to a metallic iron generated during milling processes improves the properties of CCTO in terms of ceramic capacitors.

DOI: 10.12693 /APhysPolA.126.931

PACS: $77.22 . \mathrm{Gm}, 81.05 .-\mathrm{t}$

\section{Introduction}

Ceramic materials characterized by a high value of dielectric permittivity $\left(\varepsilon^{\prime}\right)$ and low dielectric loss $(\tan \delta)$ are desirable because of their numerous possibilities for use in electronics. Currently the used materials are mainly ferroelectrics based on barium and lead oxides. Their high dielectric permittivity is associated with a structural phase transition occurring in a narrow temperature range, which limits their use in electronic devices, e.g. as capacitors. In addition, applying the mentioned toxic compounds is incompatible with the principles of green chemistry.

According to the study provided by Ramirez et al. [1] a $\mathrm{CaCu}_{3} \mathrm{Ti}_{4} \mathrm{O}_{12}$ (CCTO) compound, with a perovskite structure, has the peculiar dielectric properties, i.e. a high dielectric permittivity $\left(\varepsilon^{\prime}\right)$ (up to $10^{5}$ ), which is practically independent of frequency (from dc to $10^{6} \mathrm{~Hz}$ ) and temperature (between 100-600 K). However, the high value of the dielectric loss $(\tan \delta)$ of CCTO limits its applicability as a capacitor material $[2,3]$.

There are many descriptions of the mentioned above dielectric properties. At present a barrier mechanism $[3,4]$ is commonly accepted as the correct one. However, the nature of those barriers that lead to the colossal dielectric permittivity in CCTO is still questionable. Certain experimental results e.g. Li et al. [5], Sinclair et al. [6] indicate that the colossal dielectric permittivity is caused by the presence of internal barrier layer capacitors (IBLC), whilst others suggest surface barrier layer capacitors (SBLC) [7]. The former could stem from grain boundaries in ceramic samples and/or from boundaries between twins or other planar defects within single crystals or the crystallites of the ceramic samples. The latter could be formed by the depletion of the layers of

\footnotetext{
${ }^{*}$ corresponding author; e-mail: piotrdulian@indy.chemia.pk.edu.pl
}

Shottky for example see Felix et al. [8] or Deng et al. [9] who evidenced the existence of the interfaces between the metallic electrodes and the bulk sample.

The current research on CCTO ceramics is focused on the reducing the dielectric losses and attaining the largest possible value of the dielectric permittivity $\left(\varepsilon^{\prime}\right)$. This is possible by the substituted replacement of different ions e.g. $\mathrm{Mn}, \mathrm{Fe}, \mathrm{Nb}$ [10], La [11], Sr [12] and $\mathrm{Zr}$ [13], doping of CCTO with $\mathrm{Cr}_{2} \mathrm{O}_{3}, \mathrm{Nb}_{2} \mathrm{O}_{5}$ [14] or $\mathrm{ZrO}_{2}$ [15] and the production of two-component systems such as CCTO$\mathrm{CaTiO}_{3}$ [16], CCTO-SrTiO 3 [17], CCTO-HfO ${ }_{2}$ [18] and also the formation of multiple layered structures, e.g. $\mathrm{CCTO} / \mathrm{SiO}_{2} / \mathrm{CCTO}[19]$.

According to the opinion of Rajarabar-Darvishi et al. [20] and Bender and Pan [21], the grains' microstructure of the material is of crucial importance from the standpoint of the dielectrical properties of the material, and hence the methods used to obtain the material are critical It is challenging to find the simple and cheap synthesis technique of CCTO ceramics with the proper number of defects, grain boundaries and density.

A high-temperature solid-state synthesis is commonly used to form CCTO ceramics. However this requires the use of a temperature of about $1400 \mathrm{~K}$ in order to densify the powder. On the other hand, such conditions lead to the formation of coarse-grained products due to the occurrence of the grain growth and size inhomogeneity as well as the formation of sinters and agglomerates. It is possible to lower the sintering temperature using various additives such as $\mathrm{NiO}, \mathrm{SiO}_{2}$ [22] or $\mathrm{P}_{2} \mathrm{O}_{5}$ [23] without harming the material's dielectric properties, nevertheless this does not eliminate the problem of coarse grains. This problem can be solved by different ways, e.g. by a sol-gel method [24]. This technique owing to the thorough mixing of the precursor materials in solution and the relatively lower temperature of crystallization $(1200 \mathrm{~K})$ allows to obtain a homogeneous material with small, fine crystals and excellent chemical stoichiometry. Unfortunately, the sol-gel method is complex and requires advanced, very clean equipment, 
and organometallic reagents that are not only expensive, but also environmentally hazardous. There are also known other CCTO ceramics synthesis techniques such as controlled co-precipitation [25], precursor solution [26] and hydrothermal [27] methods. However, many of these methods enable to synthesize CCTO with fine crystals. Nevertheless, they are unpopular, because their complexities and costs preclude their use in a large-scale industrial fabrication.

In consequence, there is considerable interest in alternative synthesis techniques that can eliminate the difficulties mentioned above. A solid-state high-energy milling process [28] offers simplicity because of one-step operation, solvent-free synthesis and/or the modification of properties of the advanced products, which can activate substrates or even drive a reaction to completion at room temperature, dependent on the chemical and physical nature of the substrates. Some of the completed reactions can result in new products, as is seen in the case of perovskites, for example see [29-31]. Thus, Almeida et al. [32], Manik and Pradhan [33] and Alizadeh et al. [34] presented the mechanochemical syntheses of nanocrystalline CCTO using the different type of $\mathrm{CaO}, \mathrm{CuO}$ and $\mathrm{TiO}_{2}$ powder reactants. Unfortunately, in these three papers there are not the results of the dielectric properties of synthesized CCTO as well as the information on the influence of any impurities from a reaction vessel and balls introduced into the materials. The following article attempts to fill this gap. Recently our preliminary studies have been presented in the paper [35].

This paper is aimed to explain the advantages of the mechanochemical synthesis of polycrystalline CCTO with useful dielectric properties. Additionally, the results are compared to the CCTO ceramics that was obtained with the use of a traditional high-temperature method.

\section{Experimental}

\subsection{Chemicals}

The materials used were oxides (pure p.a. 98\%) of calcium (POCh), copper(II) (Fluka Analytical), titanium (Evonik Degussa GmbH). Zirconium oxide and metallic iron from the balls and vessel were considered as a factor that could affect the chemical structure of CCTO.

\subsection{Synthesis procedure}

2.2.1. Preparation of $\mathrm{CaCu}_{3} \mathrm{Ti}_{4} \mathrm{O}_{12}$ ceramics via a highenergy ball milling technique (samples CCTO/Fe and $C C T O / Z r)$

The $\mathrm{CaO}, \mathrm{CuO}$ and $\mathrm{TiO}_{2}$ powders were hand-mixed in a stoichiometric ratio in an agate mortar for $2 \mathrm{~h}$. Such a mixture was subjected to mechanochemical treatment in a Pulverisette 6 (Fritsch GmbH, Germany) planetary ball mill. The reactor $(250 \mathrm{ml})$ and balls of $10 \mathrm{~mm}$ in diameter of steel and zirconia were used, respectively.

Milling parameters: $\mathrm{rpm}=550$; ball to powder mass ratio: $\mathrm{BPR}=20: 1$; milling time: $5 \mathrm{~h}$.
2.2.2. Preparation of $\mathrm{CaCu}_{3} \mathrm{Ti}_{4} \mathrm{O}_{12}$ ceramics by a hightemperature solid-state reaction (sample CCTO/T)

In this case the $\mathrm{CaO}, \mathrm{CuO}$ and $\mathrm{TiO}_{2}$ powders were also mixed together in a stoichiometric ratio in an agate mortar for $2 \mathrm{~h}$ and pressed at $20 \mathrm{MPa}$ into pellet discs $4 \mathrm{~mm}$ thick and of $12 \mathrm{~mm}$ in diameter. These discs were sintered in air with the use of a Nabertherm HTC 03/15 laboratory furnace for $12 \mathrm{~h}$ at the temperature of 1220 , 1320 , and $1370 \mathrm{~K}$.

\subsection{Measurements' techniques}

$\mathrm{X}$-ray powder diffraction measurements for a phase analysis were performed on a X'Pert Phillips diffractometer using a $\mathrm{Cu} K_{\alpha}$ radiation $(\lambda=1.54178 \AA)$ between $10^{\circ}<2 \theta<90^{\circ}$ with step-width of $0.01^{\circ}$. JCPDF cards were used to identify the phases present in the samples.

The SEM images of the microstructure, morphology and elemental composition of obtained ceramics were taken with a HITACHI S-4700 instrument with X-ray EDS analysis.

The elemental compositions of the bulk samples were measured by an energy-dispersive X-ray fluorescent spectroscopy (XRF) using a XRF Bruker S4 Explorer instrument.

The dielectric spectroscopy measurements in the frequency domain were performed at frequency ranging from $20 \mathrm{~Hz}$ to $1 \mathrm{MHz}$ with the use of a LCR Agilent $4284 \mathrm{~A}$ meter and a Quatro Krio 4.0 temperature control system. The dielectric property measurements were carried out at temperature between $473 \div 173 \mathrm{~K}$ with a $5 \mathrm{~K}$ step. To perform the dielectric measurements the samples of $7 \mathrm{~mm}$ in diameter and $2.5 \mathrm{~mm}$ thick were covered with silver electrodes.

\section{Results and discussion}

\subsection{Characteristics of CCTO ceramics synthesized by two different methods}

The XRD pattern of the CCTO powder obtained mechanochemically is shown in Fig. 1. Regardless whether the reaction vessel and balls were made of zirconia $(\mathrm{CCTO} / \mathrm{Zr})$ or iron $(\mathrm{CCTO} / \mathrm{Fe}), \mathrm{CaCu}_{3} \mathrm{Ti}_{4} \mathrm{O}_{12}$ was identified in accordance with the JCPDS PDF No. 75-2188. The XRF elemental analyses show that the impurities from milling process are present in amount of 1.5 wt. $\% \mathrm{ZrO}_{2}$ and 2.2 wt.\% $\mathrm{Fe}$ in $\mathrm{CCTO} / \mathrm{Zr}$ and $\mathrm{CCTO} / \mathrm{Fe}$, respectively (this is not detectable in the XRD patterns).

In Fig. 2 the X-ray powder pattern of CCTO obtained, for comparison, via the high-temperature synthesis $(\mathrm{CCTO} / \mathrm{T})$ is shown.

The CCTO samples synthesized by mechanical treatment show the lower intensities of peaks and they are wider than those of the material obtained through the high-temperature synthesis. This indicates that the mechanochemically-obtained crystals are much smaller and display a higher defected structure. Moreover, it was stated that the sample was partially amorphous and heating for $1 \mathrm{~h}$ at the temperature of $1270 \mathrm{~K}$ improves the crystallinity of CCTO, and so the amorphous phase disappears. 


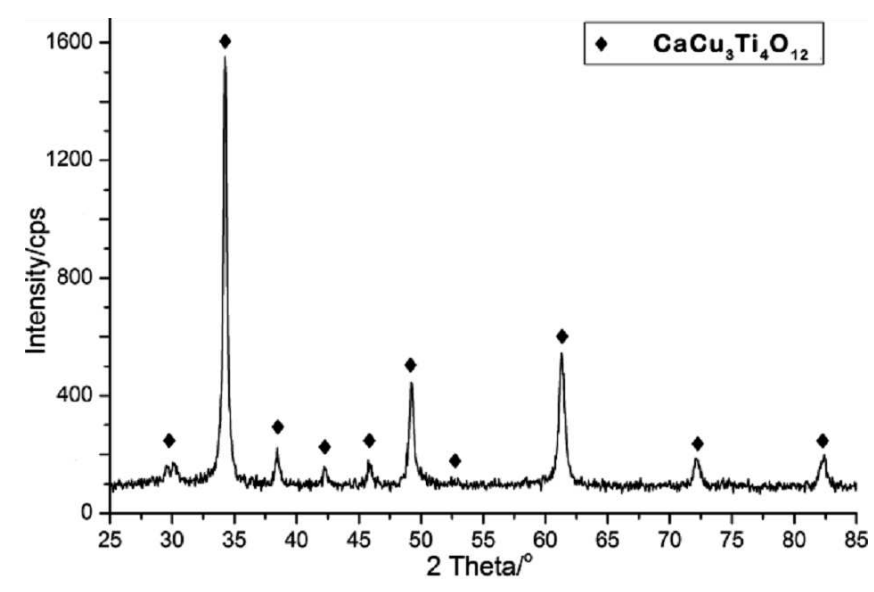

Fig. 1. XRD pattern of $\mathrm{CaCu}_{3} \mathrm{Ti}_{4} \mathrm{O}_{12} \quad(\mathrm{CCTO} / \mathrm{Zr})$ sample mechanochemically synthesized using vial and balls with zirconia.

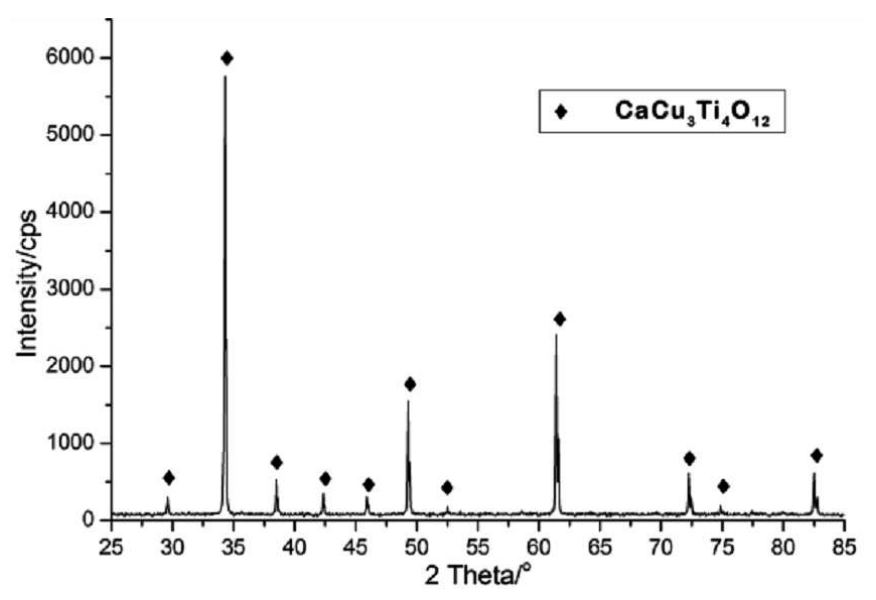

Fig. 2. XRD pattern of $\mathrm{CaCu}_{3} \mathrm{Ti}_{4} \mathrm{O}_{12} \quad(\mathrm{CCTO} / \mathrm{T})$ sample synthesized by high-temperature treatment.

\subsection{Morphological observations of different CCTO samples}

The morphological differences between the particles obtained by above mentioned two methods are illustrated in SEM photomicrographs in Fig. 3. The CCTO/T ceramics have the largest particle sizes (ranging between 1.5 and $2.5 \mu \mathrm{m}$ ) of any of the studied samples. Sinters are also visible in the material. Smaller crystals are present along the edges of the particles that are caused probably by a liquid phase of $\mathrm{CuO}$ that forms under high temperature conditions and recrystallizes when the sample is cooled, as evidenced Fang and Mei [36].

The CCTO ceramics obtained mechanochemically showed great homogeneity in the distribution of particle size $(100 \mathrm{~nm}$ and $500 \mathrm{~nm})$ without any sintering effects. The X-ray EDS elemental analysis showed the presence of inclusions of zirconia or metallic iron (the results are not presented here).

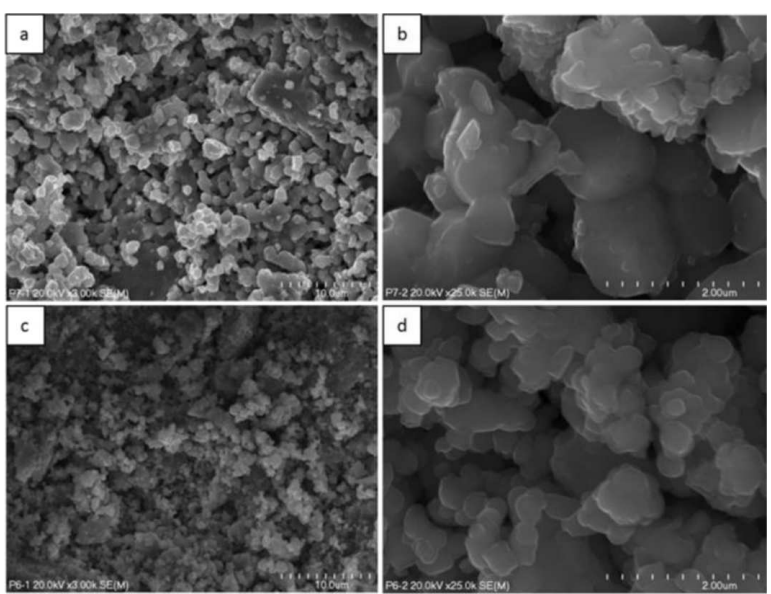

Fig. 3. SEM images of $\mathrm{CaCu}_{3} \mathrm{Ti}_{4} \mathrm{O}_{12}$ : (a) and (b) from high-temperature treatment $(\mathrm{CCTO} / \mathrm{T}),(\mathrm{c})$ and $(\mathrm{d})$ from mechanochemical synthesis (CCTO/Zr) (two different magnifications).

\subsection{Characteristics of dielectric properties of $\mathrm{CaCu}_{3} \mathrm{Ti}_{4} \mathrm{O}_{12}$ (CCTO) ceramics}

A dielectric relaxation phenomenon was used to describe the dielectric properties of the CCTO ceramics investigated at the temperature ranging from $473 \mathrm{~K}$ to $173 \mathrm{~K}$. The experimental data were presented based on the electrical permittivity and electric modulus.

The electric modulus $M *=M^{\prime}+\mathrm{i} M^{\prime \prime}$ and complex permittivity $\varepsilon^{*}$ formulae are related, i.e. $\varepsilon *=1 / M *$, and they are more thoroughly discussed elsewhere [37].

For the first time, this formula was used by Macedo et al. [38] who studied space-charge relaxation phenomena. From a physical point of view an electric modulus represents the real process of relaxation of an electrical field in the material when the electric displacement remains constant.

The formalism of electrical modulus is very sensitive to small changes in the value of capacitance, so it is among others the most suitable for the description of the electrical properties of grains in ceramic materials [39]. An additional advantage is the ability to separate intragranular (bulk), inter-granular and electrode effects of sample.

Generally, the relaxation phenomena in the frequency $(\nu)$ domain are characterized by the maximum dielectric loss $\varepsilon^{\prime \prime}(\nu)$ and the corresponding inflection point of curve dispersion $\varepsilon^{\prime}(\nu)$.

A similar description of dielectric relaxation is represented in the case of an electrical modulus but the maximum $M^{\prime \prime}(\nu)$ is shifted to a higher frequency in respect of the $\varepsilon^{\prime \prime}(\nu)$ maximum [40].

Figures 4 and 5 show the temperature dependences of the imaginary component of $M^{\prime \prime}(T)$ and $\varepsilon^{\prime \prime}(T)$, respectively at the same frequency of electric field $(\nu=1 \mathrm{kHz})$ for all three samples obtained by different methods. A visualization of the temperature dependencies allows the initial estimation of the ranges of the occurrence of relaxations processes. 


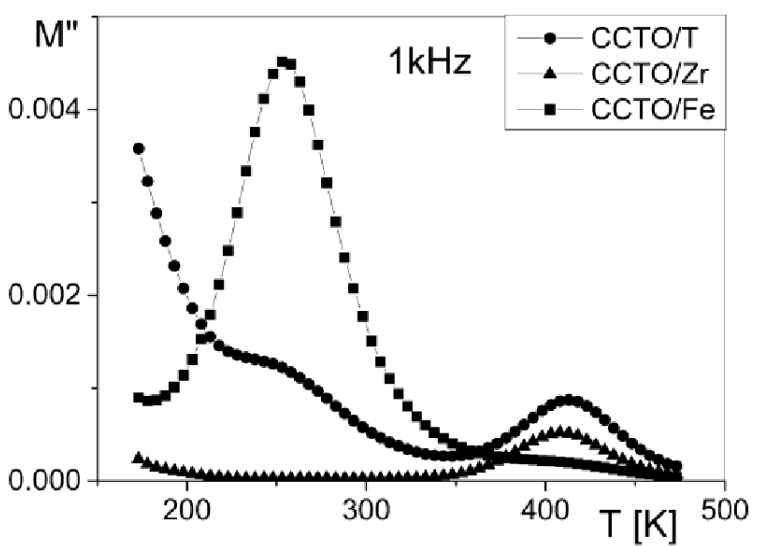

Fig. 4. Temperature dependence of imaginary part of electrical modulus $\left(M^{\prime \prime}\right)$ at $1 \mathrm{kHz}$ for $\mathrm{CaCu}_{3} \mathrm{Ti}_{4} \mathrm{O}_{12}$ (CCTO) ceramics.

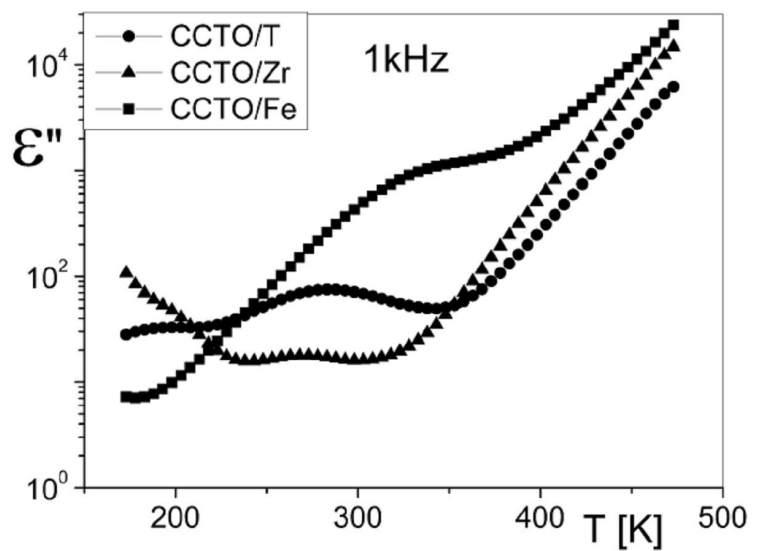

Fig. 5. Temperature dependence of imaginary part of dielectric permittivity $\left(\varepsilon^{\prime \prime}\right)$ at $1 \mathrm{kHz}$ for $\mathrm{CaCu}_{3} \mathrm{Ti}_{4} \mathrm{O}_{12}$ (CCTO) ceramics.

In the $M^{\prime \prime}(T)$ plot, at the temperature of above $350 \mathrm{~K}$ for $\mathrm{CCTO} / \mathrm{Zr}$ and $\mathrm{CCTO} / \mathrm{T}$ samples the maxima are visible that suggest the presence of relaxation processes. In contrast, on the $\varepsilon^{\prime \prime}(T)$ plot it can be seen a strong increase in the dielectric loss which is mainly connected with electrical conductivity. In turn, in the lower temperature region (below $200 \mathrm{~K}$ ), the $M^{\prime \prime}(T)$ and $\varepsilon^{\prime \prime}(T)$ plots also display changes that indicate a relaxation in all investigated samples. However these processes have a different character and will be discussed on the basis of the frequency dependence of electrical modulus and electrical permittivity.

Figure 6 presents on the complex plane the electrical modulus $M^{\prime \prime}\left(M^{\prime}\right)$ at a temperature of $423 \mathrm{~K}$ for the three investigated ceramics. Only the experimental data for the CCTO/Fe sample show a semicircular arc which clearly indicates the relaxation process and enable to calculate the time of relaxation from the maximum of $M^{\prime \prime}\left(M^{\prime}\right)$ function.

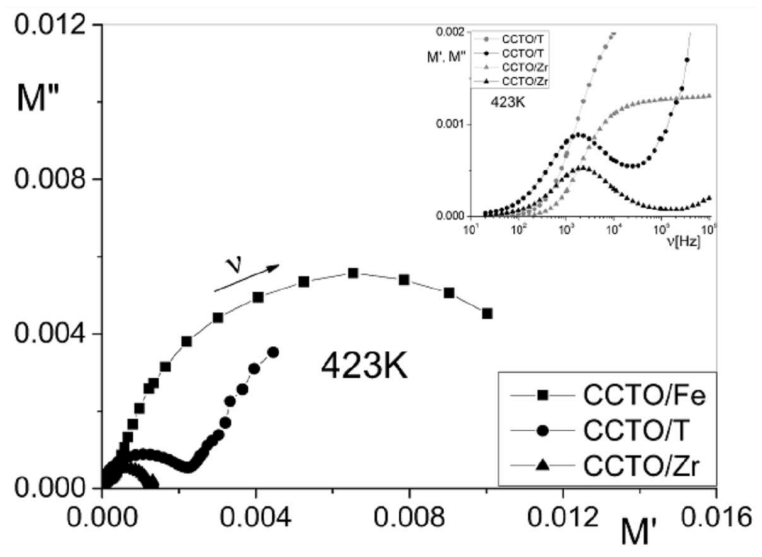

Fig. 6. Electrical modulus complex plane plots for $\mathrm{CaCu}_{3} \mathrm{Ti}_{4} \mathrm{O}_{12}$ (CCTO) ceramics at $423 \mathrm{~K}$. The inset shows an expanded view of frequency dependence of $M^{\prime}$ and $M^{\prime \prime}$ (darker symbols) for CCTO/T and CCTO/Zr samples.

The inset of Fig. 6 shows the real $M^{\prime}(\nu)$ and imaginary $M^{\prime \prime}(\nu)$ components of electric modulus as a function of frequency at a fixed temperature of $423 \mathrm{~K}$ for the $\mathrm{CCTO} / \mathrm{Zr}$ and $\mathrm{CCTO} / \mathrm{T}$ samples. By the placing of the maximum $M^{\prime \prime}$ on the frequency spectrum the relaxation times can be easier determined. For all samples, the increase in temperature shifts the $M^{\prime \prime}(\nu)$ maximum towards higher frequencies even beyond the range of the spectrum (above $10^{6} \mathrm{~Hz}$ ). For the CCTO/Zr and $\mathrm{CCTO} / \mathrm{T}$ samples, below the temperature of $350 \mathrm{~K}$ the $M^{\prime \prime}(\nu)$ maximum moves below the frequency of $20 \mathrm{~Hz}$ that is beyond the frequency measuring range.

The experimental data in a $\varepsilon^{\prime \prime}\left(\varepsilon^{\prime}\right)$ (the Cole-Cole) representation at temperature of $423 \mathrm{~K}$ has not shown due to their dominating nature of dielectric losses on the relaxation process. The imaginary component $\varepsilon^{\prime \prime}$ is around two orders of magnitude greater than the real component $\varepsilon^{\prime}$.

The dependence of the components of electric permittivity at the temperature of $423 \mathrm{~K}$ on frequency are shown in Fig. 7. The largest dispersion of $\varepsilon^{\prime}(\nu)$ is found in the $\mathrm{CCTO} / \mathrm{Fe}$ sample. For the other two samples the value of $\varepsilon^{\prime}(\nu)$ does not change very much, especially in the region below $1 \mathrm{kHz}$. The straight slopes were calculated for a $\log -\log$ plot of $\varepsilon^{\prime \prime}(\nu)$ in low frequency range, and are between 0.90 and 0.95 . These values, although close to those of dc conductivity (which has a straight slope of 1.0) suggest an extremely low frequency relaxation process which is connected to an electrical charge-carrier trapping.

In heterogeneous dielectric materials such as CCTO ceramics we can see phases with different electrical conductivities. The application of an electrical field to a sample causes the displacement of charge from the phases that are more conductive to those that are less. Especially in low frequency range a space charge and an interfacial polarization effects associated with it occur. This polarization results in the high values of $\varepsilon^{\prime}(\nu)$ and dielectric losses $\varepsilon^{\prime \prime}(\nu)$. 


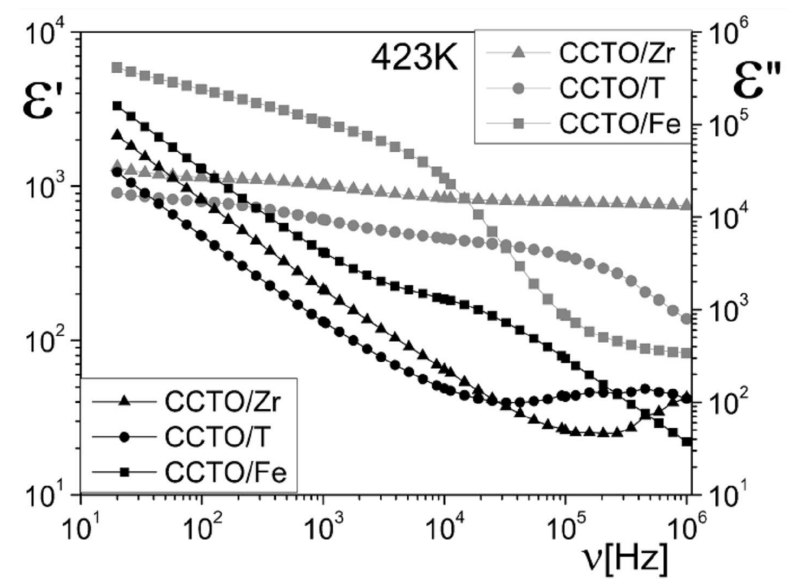

Fig. 7. Frequency dependence of real $\left(\varepsilon^{\prime}\right)$ and imaginary $\left(\varepsilon^{\prime \prime}\right)$ part of dielectric permittivity at $423 \mathrm{~K}$ for $\mathrm{CaCu}_{3} \mathrm{Ti}_{4} \mathrm{O}_{12}$ (CCTO) ceramics.

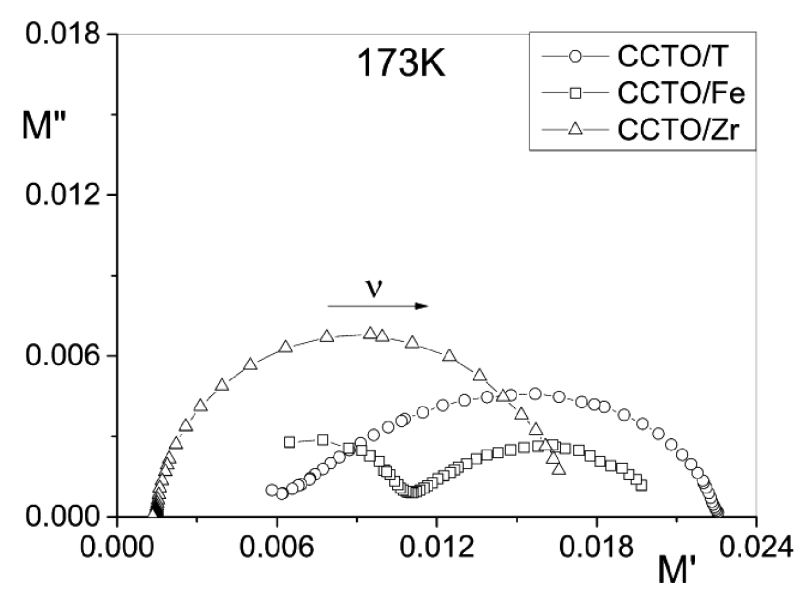

Fig. 8. Electrical modulus complex plane plots for $\mathrm{CaCu}_{3} \mathrm{Ti}_{4} \mathrm{O}_{12}$ (CCTO) ceramics at $173 \mathrm{~K}$.

Figure 8 presents on the complex plane $M^{\prime \prime}\left(M^{\prime}\right)$ the experimental data obtained at the temperature of $173 \mathrm{~K}$ for all investigated ceramics. Graphs in a semicircular shape indicate the presence of relaxation processes. The centers of all these semicircles lie below the real axis $M^{\prime}$. The degree of this lowering, which indicates the distribution of relaxation times is the smallest for $\mathrm{CCTO} / \mathrm{Zr}$. For the $\mathrm{CCTO} / \mathrm{T}$ sample the distribution of relaxation time continues to increase. It is vital to note that the graph is asymmetrical and greatly expanded, presumably it contains two superimposed semicircles. On the other hand for $\mathrm{CCTO} / \mathrm{Fe}$ in the low frequency range there is an additional semicircular arc. The centers of these arcs lie below the axis of the real component of electric modulus. At such a low temperature the relaxation processes have a different character than the same processes at the temperature of $423 \mathrm{~K}$ first of all due to a very small dielectric losses. The description of the investigated ceramics by the $M^{\prime \prime}\left(M^{\prime}\right)$ graphs show that the bulk material is heterogeneous. This may indicate a "weak" synthesis or the presence of ceramic sinters. If the sample is well synthesized (around $95 \%$ of theoretical density) and the bulk material is electrically homogenous then we have an ideal semicircle on the $M^{\prime \prime}\left(M^{\prime}\right)$ plot with the center of the semicircular arc lying on the real axis $M^{\prime}$.

The Cole-Cole plots at temperature of $173 \mathrm{~K}$ are presented in Fig. 9. A visual estimation of relaxation processes at approximately the same $\varepsilon^{\prime \prime}$ and $\varepsilon^{\prime}$ scale for all ceramics is possible only for the $\mathrm{CCTO} / \mathrm{Zr}$ sample. To scale up the $\varepsilon^{\prime \prime}\left(\varepsilon^{\prime}\right)$ graphs for the CCTO/T and CCTO/Fe samples, in the inset there were shown the frequency dependence characteristics of electric permittivity components. These characteristics provide more information on the topic of both dispersion and absorption phenomena in these materials. Normally, in the range of high frequencies an area of plateau of $\varepsilon^{\prime}(\nu)$ is related to the permittivity of grains, but low-frequency dispersions corresponds to a inter-grain or electrodes polarization [37]. Therefore, if the value of $\varepsilon^{\prime}(\nu)$ lies outside of the area of the plateau the permittivity does not describe the intrinsic changes in the grains of the material.

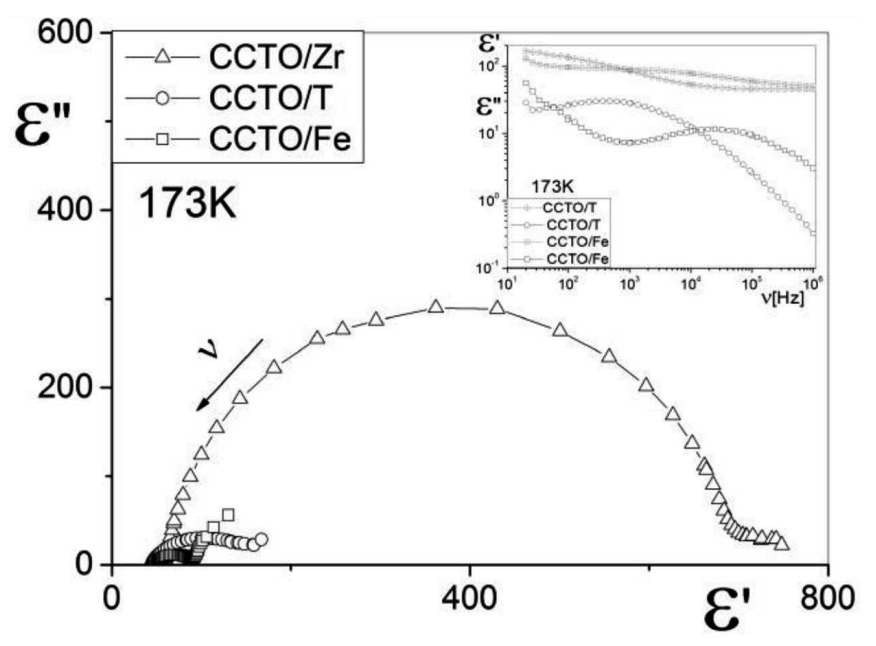

Fig. 9. Dielectric permittivity complex plane plots for $\mathrm{CaCu}_{3} \mathrm{Ti}_{4} \mathrm{O}_{12}$ (CCTO) ceramics at $173 \mathrm{~K}$. The inset shows an expanded view of frequency dependence of $\varepsilon^{\prime}$ and $\varepsilon^{\prime \prime}$ (empty symbols) for CCTO/T and CCTO/Fe samples.

For the investigated ceramics a perfect response was not obtained from the bulk material, meaning a flat, frequency-independent region. The decrease of $\varepsilon^{\prime}(\nu)$ with increasing frequency, confirms the electrical inhomogeneity of the sample.

Figure 10 shows Arrhenius plots for the relaxation times described by the following equation: $\tau=\tau_{0} \exp (-$ $E \mathrm{a} / k T)$, where $\tau_{0}$ is the pre-exponential term, $E_{\mathrm{a}}$ is the activation energy and $k$ is the Boltzmann constant. The relaxation times $\tau$ for all investigated samples at the temperatures from the entire temperature range were determined from the spectrum of $M^{\prime \prime}(\nu)$. 


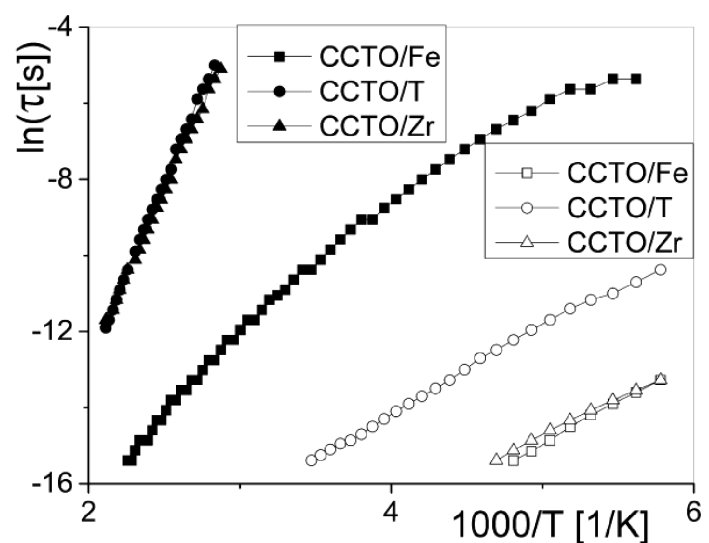

Fig. 10. Arrhenius plots of bulk (empty symbols) and grain boundary (filled symbols) relaxation times data for $\mathrm{CaCu}_{3} \mathrm{Ti}_{4} \mathrm{O}_{12}$ (CCTO) ceramics.
Literature value [39] of the activation energy in grain for CCTO determined based on the relaxation process is around $0.06 \mathrm{eV}$. In contrast, the values of activation energy around of $0.65 \mathrm{eV}$ comes from localized charge carrier (hopping conduction). Generally, the time of relaxation $\tau$ is much larger at the grain boundaries than in grains.

In agreement with the IBLC model, it is possible to confirm that the process of relaxation at the temperatures above $350 \mathrm{~K}$ corresponds to a Maxwell-WagnerSillars polarization model. The value of the activation energy determined for $\mathrm{CCTO} / \mathrm{Zr}$ and $\mathrm{CCTO} / \mathrm{T}$ samples is about $0.8 \mathrm{eV}$ while for $\mathrm{CCTO} / \mathrm{Fe}$ in the same temperature range is $0.4 \mathrm{eV}$. According to Guo et al. [41] the source of the potential barrier is related to the $\mathrm{Cu}$ ions, which segregate themselves into the grain boundaries. The activation energy data that relate to the relaxation process are presented in Table.

TABLE I

Relaxation process data for $\mathrm{CaCu}_{3} \mathrm{Ti}_{4} \mathrm{O}_{12}$ (CCTO) samples.

\begin{tabular}{l|c|c|c}
\hline \hline Composition & CCTO $/ \mathrm{Zr}$ & CCTO/T & CCTO/Fe \\
\hline Temperature range $[\mathrm{K}] /$ Time relaxation range $[\mathrm{s}]$ & \multicolumn{2}{|c|}{ Activation energy $[\mathrm{eV}] /$ Pre-exponential term $\tau_{0}[\mathrm{~s}]$} \\
\hline $473 \div 353 / 8 \times 10^{-6} \div 6 \times 10^{-3}$ & $0.77 / 5.3 \times 10^{-14}$ & $0.83 / 1.0 \times 10^{-14}$ & $0.40 / 6.4 \times 10^{-12}$ \\
$213 \div 173 / 2 \times 10^{-7} \div 2 \times 10^{-6}$ & $0.17 / 2.4 \times 10^{-11}$ & & $0.19 / 5.3 \times 10^{-12}$ \\
$288 \div 173 / 2 \times 10^{-7} \div 3 \times 10^{-5}$ & & $0.19 / 8.7 \times 10^{-11}$ & \\
\hline
\end{tabular}

The pre-exponential term, $\tau_{0}$ was determined from equation $\ln \tau=\ln \tau_{0}-E \mathrm{a} / k T$ assuming that $1 / T \rightarrow 0$.

\section{Final remarks and conclusions}

The $\mathrm{CaCu}_{3} \mathrm{Ti}_{4} \mathrm{O}_{12}$ ceramic powder was synthesized with the use of two different methods: via the mechanochemical synthesis at room temperature and by the high-temperature treatment of reagents. The properties of materials obtained by these two methods were compared, and the results showed that the time required for synthesis can be shortened when a thermal method is used from $12 \mathrm{~h}$ to between 1.5 and $5 \mathrm{~h}$ (dependent on milling energy).

For the first case, the effects of impurities introduced by the process of milling $\left(\mathrm{ZrO}_{2}\right.$ and $\left.\mathrm{Fe}^{0}\right)$ on the physical and dielectrical properties are presented, as well as the methods by which such additives can be intentionally and rationally introduced for the optimization of the useful characteristics of the ceramic materials.

The microstructural tests of the differently-obtained materials demonstrate that the grain morphology and the number of present defects are important in determining various properties.

The results of dielectric property tests can be characterized as follows: in the frequency domain there are the different areas of dielectric relaxation. Practically across the entire temperature and frequency measurement range for all samples the values of dielectric permit- tivity and electrical modulus change. These changes contradict the general principle that the dielectric permittivity of CCTO is independent of frequency between $20 \mathrm{~Hz}$ and $1 \mathrm{MHz}$ at room temperature. The activation energy related to different electro-active regions is determined on the basis of electrical modulus. At higher-temperature conditions (above $350 \mathrm{~K}$ ), the relaxation processes are characteristic at the grain boundaries. The macroscopic Maxwell-Wagner-Sillars model of surface polarization, which describes this relaxation, probably refers to the heterogeneous distribution of oxygen atoms on the surface and in the interior of the sample. In turn, this distribution may be a result of the phase segregation of a $\mathrm{Cu}-$ rich layer on the surface of the sample. Below the temperature of $250 \mathrm{~K}$ and at a frequency of approximately $100 \mathrm{kHz}$, the dielectric relaxation is observed, similar to a relaxation of Debye-type. According to the IBLC model, this type of relaxation may be the surface polarization effects in both the grains on or in the grain boundaries.

\section{Acknowledgments}

This study was supported by the National Science Centre Poland, Project DEC-2012/05/N/ST8/03764 and by the Polish Ministry of Science and Higher Education DS/C-1/KWC/2014. 


\section{References}

[1] A.P. Ramirez, M.A. Subramanian, M. Gardel, G. Blumberg, D. Li, T. Vogt, S.M. Shapiro, Solid State Commun. 115, 217 (2000).

[2] C.-H. Mu, P. Liu, Y. He, J.-P. Zhou, H.-W. Zhang, J. Alloys Comp. 471, 137 (2009).

[3] P. Lunkenheimer, R. Fichtl, S.G. Ebbinghaus, A. Loidl, Phys. Rev. B Condens. Matter Mater. Phys. 70, 172102 (2004).

[4] X.-H. Zheng, C. Zhang, X. Liu, D.-P. Tang, J. Xiao, Chin. J. Nonferr. Met. 21, 630 (2011).

[5] J. Li, A.W. Sleight, M.A. Subramanian, Solid State Commun. 135, 260 (2005).

[6] D.C. Sinclair, T.B. Adams, F.D. Morrison, A.R. West, Appl. Phys. Lett. 80, 2153 (2002).

[7] C.C. Wang, L.W. Zhang, Appl. Phys. Lett. 88, 042906 (2006).

[8] A.A. Felix, M.O. Orlandi, J.A. Varela, Solid State Commun. 151, 1377 (2011).

[9] G. Deng, T. Yamada, P. Muralt, Appl. Phys. Lett. 91, 202903 (2007).

[10] P. Leret, J.F. Fernandez, J. Frutos, D. FernándezHevia, J. Eur. Ceram. Soc. 27, 3901 (2007).

[11] L. Feng, X. Tang, Y. Yan, X. Chen, Z. Jiao, G. Cao, Phys. Status Solidi A Appl. Mater. Sci. 203, 22 (2006).

[12] H. Xue, X. Guan, R. Yu, Z. Xiong, J. Alloys Comp. 482, 14 (2009).

[13] H. Yu, W. Zhang, J. Liu, H. Liu, Mater. Sci. Forum 687, 375 (2011).

[14] S. Kwon, C.-C. Huang, E.A. Patterson, D.P. Cann, Mater. Lett. 62, 633 (2008).

[15] E.A. Patterson, S. Kwon, C.-C. Huang, D.P. Cann, Appl. Phys. Lett. 87, 182911 (2005).

[16] Y. Yan, L. Jin, L. Feng, G. Cao, Mater. Sci. Eng. $B$ 130, 146 (2006).

[17] L. Feng, Y. Wang, Y. Yan, G. Cao, Z. Jiao, Appl. Surf. Sci. 253, 2268 (2006).

[18] W.-X. Yuan, S.K. Hark, J. Eur. Ceram. Soc. 32 , 465 (2012).

[19] L. Fang, M. Shen, J. Yang, Z. Li, Solid State Commun. 137, 381 (2006).

[20] A. Rajarabar-Darvishi, W.-L. Li, O. SheikhejadBishe, L.-D. Wang, X.-L. Li, N. Li, W.-D. Fei, Trans. Nonferr. Met. Soc. China 21, 400 (2011).
[21] B.A. Bender, M.J. Pan, Mater. Sci. Eng. B - SolidState-Mater. Adv. Technol. 117, 339 (2005).

[22] L. Liu, Y. Huang, Y. Li, D. Shi, S. Zheng, S. Wu, L. Fang, C. Hu, J. Mater. Sci. 47, 2294 (2012).

[23] S. Goswami, A. Sen, Ceram. Int. 36, 1629 (2010).

[24] L. Liu, H. Fan, P. Fang, X. Chen, Mater. Res. Bull. 43, 1800 (2008).

[25] B. Barbier, C. Combettes, S. Guillemet-Fritsch, T. Chartier, F. Rossignol, A. Rumeau, T. Lebey, E. Dutarde, J. Eur. Ceram. Soc. 29, 731 (2009).

[26] N. Banerjee, S.B. Krupanidhi, J. Alloys Comp. 509, 4381 (2011)

[27] S. Sen, P. Sahu, K. Prasad, Mater. Sci.-Poland 28, 265 (2010).

[28] M. Senna, T. Kinoshita, Y. Abe, H. Kishi, C. Ando, Y. Doshida, B. Stojanovic, J. Eur. Ceram. Soc. 27, 4301 (2007).

[29] K. Wieczorek-Ciurowa, P. Dulian, A. Nosal, J. Domagała, J. Therm. Anal. Calorim. 101, 471 (2012).

[30] P. Dulian, W. Bąk, K. Wieczorek-Ciurowa, C. Kajtoch, Mater. Sci.-Poland 31, 462 (2013).

[31] J.D. Bobić, B.D. Stojanović, C.O. Paiva-Santos, L.J. Zivkovic, M.M. Vijatović, M. Cilense, Ferroelectrics 368, 145 (2008).

[32] A.F.L. Almeida, R.S. de Oliveira, J.C. Góes, J.M. Sasaki, A.G. Souza Filho, J. Mendes Filho, A.S.B. Sombra, Mater. Sci. Eng. B 96, 275 (2002).

[33] S.K. Manik, S.K. Pradhan, Physica E 33, 160 (2006).

[34] M. Alizadeh, H.A. Ardakani, R. Amini, M.R. Ghazanfari, M. Ghaffari, Ceram. Int. 39, 3307 (2013).

[35] P. Dulian, W. Bąk, K. Wieczorek-Ciurowa, Cz. Kajtoch, Key Eng. Mater. 543, 326 (2013).

[36] T.T. Fang, L.T. Mei, J. Am. Ceram. Soc. 90, 638 (2007).

[37] J. East, D.C. Sinclair, J. Mater. Sci. Lett. 16, 422 (1997).

[38] P.B. Macedo, C.T. Moynihan, R. Bose, Phys. Chem. Glasses 13, 171 (1972).

[39] B. Shri Prakash, K.B.R. Varma, J. Phys. Chem. Solids 68, 490 (2007).

[40] M.P. Dasari, K. Sambasiva Rao, P. Murali Krishna, G. Gopala Krishna, Acta Phys. Pol. A 119, 387 (2011).

[41] M. Guo, T. Wu, T. Liu, S-X. Wang, X-Z. Zhao, J. Appl. Phys. 99, 124113 (2006). 